\title{
Cluster of conferences MedChem 2015
}

$2^{\text {nd }}$ Russian Conference on Medicinal Chemistry and $2^{\text {nd }}$ Youth School-Conference on Medicinal Chemistry and $6^{\text {th }}$ Russian-Korean Conference "Current Issues of Biologically Active Compounds Chemistry and Biotechnology" will be held during July 5-10, 2015 in the House of Scientists of the Novosibirsk Scientific Center, located in a picturesque suburb of Novosibirsk.

The aim of the Conferences is to enhance interaction and cooperation of industry and academia scientists working in the field of medicinal and bioactive compounds chemistry as well as biotechnology and to develop scientific relations between Russia, Korea, and other countries.

\section{$2^{\text {nd }}$ Russian Conference on Medicinal Chemistry and $2^{\text {nd }}$ Youth School-Conference on Medicinal Chemistry}

\author{
Scientific Program
}

- New developments in drug discovery

- Novel synthetic and technological approaches in medicinal chemistry

- Predictive tools, virtual screening, bio- and cheminformatics

- ADME/Tox and drug delivery

\section{$6^{\text {th }}$ Russian-Korean Conference "Current Issues of Biologically Active Compounds Chemistry and Biotechnology"}

\section{Scientific Program}

- Isolation, purification, and identification of bioactive compounds

- Synthetic transformations of bioactive compounds

- Bioactivity evaluation for natural and synthetic products

- Food and biological additives from terrestrial and marine organisms

- New trends in technology and biotechnology of natural products for production of pharmaceuticals, cosmeceuticals, nutraceuticals, and agricultural preparations

The Conferences will include plenary lectures, oral communications and poster sessions. Participation by correspondence is also possible.

\section{Contacts}

Scientific Secretary of the Conferences - Prof. Konstantin P. Volcho

E-mail: medchem2015@nioch.nsx.ru

Telephone: +7 (383) 3308870 (9:00-17:00, Time Zone - GMT +06:00)

Fax: +7 (383) 330-97-52 (twenty-four-hour)

Mail: Novosibirsk Institute of Organic Chemistry, Acad. Lavrentyev Avenue 9, Novosibirsk 630090, Russia

Web-site: web.nioch.nsc.ru/medchem2015 